\title{
Modelos críticos e representações da oralidade africana
}

\author{
Ana Mafalda Leite \\ Universidade de Lisboa
}

\begin{abstract}
RESUMO: OS ESTUDOS CRIITICOS SOBRE LITERATURAS AFRICANAS DE LÍNGUA PORTUGUESA TÊM PARTILHADO DE UMA CONTRIBUIÇÃO TEÓRICA ESTRANGEIRA FUNDAMENTAL, NOMEADAMENTE ORIUNDA DO MUNDO FRANCÓFONO OU ANGLÓFONO QUE, POR RAZÕES HISTÓRICAS, TÊM UM PERCURSO EDITORIAL E DE PESQUISA MAIS ANTIGO. OS ENSAIOS E TEORIZACCÃO PROVENIENTES DESTAS DUAS ÁREAS CONFIRMAM QUE SÓ UM CONHECIMENTO APROFUNDADO DAS REALIDADES CULTURAIS SUBJACENTES AO TEXTO LITERÁRIO AFRICANO PERMITIRÁ CONFERIR AOS TEXTOS LITERÁRIOS A SUA POLIVALEENCIA CULTURAL, O SEU CARÁCTER DIFERENCIAL.

RESUMEN: LOS ESTUDIOS CRÍTICOS SOBRE LITERATURAS AFRICANAS DE LENGUA PORTUGUESA VIENEN COMPARTIENDO DE UNA CONTRIBUICIÓN TEÓRICA EXTRANJERA FUNDAMENTAL, EN PARTICULAR LAS QUE VIENEN DEL MUNDO FRANCÓFONO Y ANGLÓFONO QUE, POR RAZONES HISTÓRICAS, TIENEN UNA TRAYECTORIA EDITORIAL Y DE INVESTIGACIÓN MÁS ANTIGUA. LOS ENSAYOS Y LAS TEORIZACIONES PROCEDIENTES DE LAS DOS ÁREAS CONFIRMAN QUE SÓLO EL CONOCIMIENTO PROFUNDIZADO DE LAS REALIDADES CULTURALES SUBYACENTES AL TEXTO LITERARIO AFRICANO PERMITE ATRIBUIR A LOS TEXTOS LITERARIOS SU POLIVALENCIA CULTURAL, SU CARÁCTER DIFERENCIAL.
\end{abstract}

PALAVRAS-CHAVE: BIBLIOGRAFIA FRANCÓFONA, ANGLÓFONA, REPRESENTAÇÕES, ORALLDADE, LITERATURA MOC,AMBICANA.

PALABRAS-CLAVE: BIBLIOGRAFIA FRANCÓFONA, ANGLÓFONA, REPRESENTACIONES DE LA ORALIDAD, LITERATURA MOZAMBICANA. 
s estudos críticos sobre Literaturas Africanas de língua portuguesa têm partilhado de uma contribuição teórica estrangeira fundamental, nomeadamente oriunda do mundo francófono ou anglófono que, por razões históricas, têm um percurso editorial e de pesquisa mais antigo. Os ensaios e teorização provenientes destas duas áreas confirmam que só um conhecimento aprofundado das realidades culturais subjacentes ao texto literário africano - por vezes com vertentes teóricas especificamente africanas - permitirá conferir aos textos literários a sua polivalência cultural, o seu carácter diferencial.

Com efeito, de acordo com o ponto de vista da crítica africana, os textos literários caracterizam-se pela mobilidade da sua simbolização e convocam uma multiplicidade de metodologias para a sua descodificação, ou para a fruição completa das suas várias interferências, linguísticas, culturais, simbólicas, míticas, enfim, semióticas.

A obra de Locha Mateso La Littérature Africaine et sa Critique (1986) tem interesse em servir como elemento de referência neste domínio, uma vez que faz um historial das principais tendências críticas no campo francófono. Situa as principais fases da produção crítica sobre a literatura africana, nomeadamente, referindo um percurso que se inicia com a crítica colonial, o envolvimento com a época dos nacionalismos africanos e a reivindicação negritudiana, até à instituição da área como disciplina universitária, nas universidades africanas e francesas.

A discussão sobre a validade da contribuição crítica de africanistas europeus e do contributo das escolas ocidentais começa quando os primeiros africanos reivindicam métodos tradicionais, baseando-se na existência secular de uma 'escola' e pensamento críticos no domínio da oratura, e ao evidenciarem o desconhecimento destas poéticas, por parte da crítica de origem ocidental.

Semelhante postura, que tem na sua base a dicotomia Oralidade/ Escrita, levada ao seu extremo, considerando que a crítica mais eficaz seria aquela culturalmente mais enraizada, acabaria por efectuar-se num quadro já nem sequer nacional, mas étnico. Thomas Melone é um dos representantes deste tipo de tendência etnológica e ancestralizante, e de teses que conduziram a um impasse, uma vez que, entre outros aspectos, se punha em causa, a origem não africana dos pesquisadores.

O Colóquio de Leiden (1977) sobre a Crítica Literária Africana discutiu questões como a especificidade do discurso crítico africano, promovendo o 
ecletismo como regra, e o contributo de vários tipos de modelos críticos, entre os quais, naturalmente, os tradicionais.

Locha Mateso expõe vários dos percursos críticos que posteriormente tiveram lugar, nomeadamente a partir de ensaios de origem universitária, salientando, entre outros, a crítica sociológica de Sunday Anozié, a crítica estilística de Zadi Zaouru, o modelo linguístico de J-P. Makouta M’Boukou , tentando fazer uma tipologia do discurso crítico africano, reconhecendo o contributo incontornável das correntes críticas ocidentais no desenvolvimento dos estudos africanos, especialmente ao referir a importância do valor heurístico do conceito de "dialogismo", como sendo particularmente operatório no estudo das culturas não europeias, sujeitas à interpenetração de sistemas culturais diferentes: "Ainsi dans le domaine artistique ou littéraire, on peut mettre en rapport les traditions orales et les principes de création littéraire moderne, les interférences linguistiques dans les techniques d'écriture (...)" 1986:367.

O texto de Locha Mateso, "Le modèle traditionnel", incluído na obra referida (1986), tem especial interesse porque desenvolve uma abordagem teórica e metodológica distinta, que assenta sobretudo na especificação da relação entre a tradição oral africana e o romance moderno, encarada de um ponto de vista não ortodoxo, e representado pela obra, fundamental, de dois autores.

O primeiro, Mohamadou Kane, ensaísta senegalês, autor de Roman Africain et Tradition (1983), procura novas e mais profundas abordagens, centrandose particularmente em dar conta da sobrevivência da tradição num contexto de modernização, consistindo o trabalho do crítico em salientar a continuidade relativa do discurso tradicional oral no discurso escrito. A oralidade, modelo do discurso romanesco, comporta segundo Kane dois aspectos complementares: o "literário" concretizado pelo vasto domínio da literatura oral, e o aspecto não verbal, em que se inscreve a sageza milenar africana.

É a partir da literatura oral que o autor constrói o seu modelo teórico, procurando detectar as "formas" da sobrevivência da oralidade no romance moderno. São essencialmente seis aspectos que o autor refere: Estrutura linear, Mobilidade temporal e espacial, A viagem iniciática, Carácter autobiográfico, Estrutura dialógica e Imbrincação de géneros.

Assim, segundo Kane, a literatura oral, nomeadamente o género predilecto, o conto, desenvolve uma história simples e uma acção linear e, semelhante 
alinhamento da intriga, visa evitar a confusão do ouvinte; do mesmo modo o romance moderno africano recupera esta técnica narrativa, insistindo na unidade de acção, e na simplicidade da intriga, aspectos, aliás, que podem levar um crítico, não conhecedor das técnicas orais, a considerá-los como factor de inexperiência ou inabilidade do escritor.

A mobilidade temporal e espacial é outra das formas de sobrevivência da literatura oral que caracteriza o romance africano, em que o itinerário do herói evolui na mudança, partindo de uma situação de desequilíbrio ou equilíbrio, que tende a inflectir no seu contrário, prevalencendo uma moralidade final. Ligada a esta característica, a viagem iniciática, segundo Kane, simboliza o drama de África, dividida entre a tradição e a modernidade, e a viagem implica aprendizagem, conhecimento, didactismo.

Por outro lado, se a literatura tradicional está mais vocacionada para os valores comunitários do que individuais, o romance africano revela uma vertente autobiográfica muito forte, componente inovadora em relação à tradição; a estrutura dialógica autor-narrador/leitor convoca os procedimentos existentes entre o contador e seu auditório, uma vez que a produção de formas breves, como as máximas, adivinhas, provérbios, pressupõe, pelo menos, a presença de dois indivíduos; a omnisciência e a polivalência do contador tradicional sobrevive nas formas do narrador, que interfere e não hesita em invadir a narrativa e distanciar-se de novo.

A imbrincação de géneros é a sexta característica da sobrevivência da oralidade no romance africano. Kane explica que na literatura tradicional não há fronteira rígida entre os diversos géneros. "Au sein d’un même conte, le récit et le chant, la musique et le jeu du conteur, créent vite l'impression d'un véritable théâtre. L'histoire et la légende se marient intimement; la poésie et le chant sont partout présents" (1983:566), e que o romancista africano integra diferentes formas da literatura oral, no decorrer da narrativa, a fim de insistir na função didáctica e moralizante, próprias dos universos narrativos africanos, tanto orais, como, agora, os escritos.

Concluindo, a originalidade do romance africano, de acordo com o ensaísta, resulta de uma dupla herança, tradicional e moderna, em que a oralidade sobrevive nas práticas de escrita.

Se alguns dos aspectos estudados, minuciosamente, por Kane continuam a ser úteis, outros parecem ter perdido a sua pertinência com a produção 
literária pós-colonial, mais recente. Com efeito o corpus de Kane centrouse, em especial, em romances da década de sessenta, cuja temática se centrava no conflito de culturas. No entanto, julgamos operatórios vários dos aspectos apresentados.

Com efeito, algumas das particularidades das literaturas africanas de língua portuguesa residem nesta espécie de processo, temporalmente desnivelado em relação às suas congéneres em outras línguas. O desenvolvimento do romance moçambicano, em que nosso corpus se orienta, inicia-se na década de oitenta, bem como a sua vertente temática da conflitualidade cultural.

Antes da independência, o registo romanesco é praticamente inexistente , e precário, prevalecendo a publicação, também incipiente, do conto. Por outro lado, a política, de base marxista, que prevaleceu durante a primeira década pós-colonial, retraiu os movimentos culturais nativistas, em favor de uma postura cultural ocidentalizada, fenómeno, aliás comum, aos outros países africanos de língua portuguesa. Estas particularidades históricas e culturais explicam, parcialmente, o surgimento tardio na literatura moçambicana de uma vertente, mais acentuadamente indigenista, que tem vindo a desenvolver-se, em particular a partir da década de noventa, com a publicação de romances e contos que tematizam e absorvem, recriados, nas formas discursivas, os intertextos das poéticas e tradições orais.

O segundo autor, mencionado por L. Mateso, que reflecte de forma original sobre o modelo tradicional na crítica africana, recuperando e desenvolvendo algumas das teses de Kane, é M. Ngal.

Ensaísta e escritor, Ngal preconiza que o autor africano se deve inspirar nos mecanismos de criação próprios da África tradicional e que o crítico da literatura africana deve orientar o seu estudo no sentido de descobrir no texto moderno as marcas dessa tradição. A sua obra romanesca, de que se destaca Giambatista Viko ou Le Viol du Discour Africain e L'Errance, é uma alegoria em que Ngal esboça as suas concepções sobre a influência da tradição oral africana na construção do romance moderno.

Ngal define a oralidade como "tradição oral", ou seja, o testemunho transmitido oralmente por uma geração às seguintes; ao crítico compete reconhecer os "lugares textuais" onde se intertextualiza a oralidade; todavia, além do reconhecimento de uma textualidade reconhecível, como por exemplo o uso do provérbio, do conto, o autor assinala as declarações de intenção paratextuais, 
como as introduções, dedicatórias, títulos, subtítulos, etc, bem como considera fundamental um sólido conhecimento antropológico, que permita o reconhecimento de certos símbolos e atitudes mentais características do espaço tradicional; no entanto, o autor considera que as marcas de oralidade constituem um inventário em aberto, e susceptível de múltiplas reformulações, e não um inventário constante, como o proposto por Kane.

Nos romances de Ngal há abolição da fronteira discursiva entre narração e teorização crítica; as narrativas são usadas como um pretexto para a reflexão de pressupostos teóricos e estéticos. O personagem, Viko, professor universitário, ocidentalizado e profundamente alienado, é poeta e ensaísta. A sua obra romanesca conhece, no entanto, alguns impasses. Procura, então, na tradição oral uma forma de desbloquear o seu discurso narrativo. É acusado pelos sábios africanos de ignorância e desconhecimento. Condenado a uma errância pelas tradições africanas, Viko viaja demorada e iniciaticamente pelo interior de África, a fim de descobrir a riqueza da oralidade e em busca de uma escrita original.

O corpus de textos orais a que o escritor recorre, vão sendo comentados pela sua vertente ensaística, bem como as técnicas de narração, manipulando o narrador de forma a aproximá-lo do contador; deste modo Ngal demonstra, por exemplo, que o narrador, como na tradição oral, desempenha um papel primordial, aproximando o acto de fala ao acto de criação.

Se na tradição oral as produções assumem uma dimensão de obra colectiva, a escrita assume, também, na obra do escritor africano, um papel de recriação do legado colectivo, impregnando-o de novas modalizações; o autor insiste nas noções de tempo e de espaço, considerando que o escritor deve instalar-se numa espécie de eternidade, num tempo e espaço primordiais, tempo e espaço da criação. É isto que o contador de histórias africano faz, mestre do verbo; insiste também na reabilitação de um 'código de arte africana', impregnando a narrativa de uma estética do maravilhoso, e reafirma uma necessária prática da intertextualidade.

Concluindo, ao contrário de Kane, que define inequivocamente um número restrito de estruturas orais presentes no romance africano moderno, Ngal propõe um modelo crítico que, tendo por base a tradição oral, procura, no entanto, uma linguagem crítica diversificada, que não rejeita a herança da estética europeia. É precisamente aí que, segundo Ngal, reside a originalidade do romance africano, na criação livre e eclética do escritor. 
Julgamos que as propostas de Kane e Ngal em relação a um modelo crítico se complementam e, especialmente a última, apesar de momentos de certa radicalização, propõe uma abertura teórica e de análise úteis para o trabalho analítico sobre os modelos críticos das representações da oralidade nos textos literários africanos.

Um segundo texto, de Bill Ashcroft et al., "African Literary Theories"1 permite situar e complementar a discussão sobre a eficácia e o historial crítico do modelo tradicional, do ponto de vista dos africanos anglófonos. A discussão nasce na década de sessenta em torno dos programas curriculares oferecidos pelos departamentos de Literatura Inglesa das universidades de Ibadan, Lagos e Makerere. Escritores como Chinua Achebe e Wole Soyinka defendem uma estética africana, em que o papel social do artista africano é fundamental, distanciando-se daquilo que é designado como "preocupação europeia com a experiência individual".

Esta teoria social e funcional modelou o trabalho da crítica anglófona da década de sessenta até praticamente aos anos oitenta, insistindo-se na função social e comunitária que a literatura africana herda da tradição oral; outro ponto de discussão é a demanda da africanidade da literatura e a rejeição de leituras críticas de cariz universal.

O ensaio de Achebe "Colonialist criticism" - “(...)I should like to see the word universal banned altogether from discussions of African literature until such a time as people cease to use it as a synonym for the narrow, selfserving parochialism of Europe." - é paradigma de um posicionamento crítico que defende a "descolonização" da literatura africana e reafirma a importância de pesquisar, teorizar, o monumental legado oral africano, equivalente, segundo o autor, à tradição literária europeia.

Estas posições atingiram o seu radicalismo máximo como grupo crítico Bolekaja, representado pelos nigerianos Chinweizu, Jemie e Mandubuike que, partindo das asserções de Achebe, consideram que a literatura africana tem as suas próprias tradições, modelos e normas, rejeitando qualquer interferência europeia; Wole Soyinka no seu artigo "Neo-Tarzanism: the poetics of pseudo-tradition", critica a atitude essencialista e reducionista dos Bolekaja,

1 ASHCROFT, Bill et al. "African Literary Theories". The Empire Writes Back. London: Routledge, 1989. p.123-132. 
não negando a importância do legado oral, mas afirmando a inevitável hibridação cultural resultante da história da presença colonial.

Semelhante visão neo-romântica dos africanos, de que a originalidade ou a essencialidade das narrativas africanas deve ser determinada apenas pela forma como filtram as tradições orais, parece-nos desajustada dos diferentes percursos de cada uma das literaturas nacionais, do diverso e heterogéneo continente africano, e ainda eivada de preconceitos.

Outra posição radical, já na década de oitenta, é a do escritor queniano Ngugi wa Thiong'o que reivindica a escrita das literaturas africanas em línguas nacionais, começando por dar o exemplo ao escrever em gykuyu ou em ki-swahili, e ao considerar que as literaturas africanas vivem uma fase de transição, designando-as por Literaturas Afro-Europeias.

A crítica anglófona desenvolveu também, mais ou menos simultaneamente, uma vertente de incidência marxista, e muitos dos ensaios procuram reafirmar o valor social e político da literatura, sublinhando que a visão indigenista da crítica ocupa menos relevância do que o papel de intervenção da prática social da escrita, na luta para a libertação das sociedades africanas da injustiça económica, retrocesso e corrupção. Saliente-se a este respeito, em especial, o trabalho do crítico zimbabweano Emmanuel Ngara.

No entanto, a crítica anglófona tem continuado a reflexão sobre a relação do escritor moderno com as práticas da oralidade, relativizando as posturas radicais, mas, sempre, aprofundando o modelo crítico tradicional, e o ensaísta Abiola Irele considera que, embora havendo transformações na cultura africana, pelo moderno impacto da escrita, a oralidade continua a ser o paradigma central na literatura africana:

Despite the undoubted impact of print culture on African experience and its role in the determination of new cultural modes, the tradition of orality remains predominant, serving as a central paradigm for various kinds of expression on the continent (...) In this primary sense, orality functions as the matrix of an African mode of discourse, and where literature is concerned, the griot is its embodiment in every sense of the word. Oral literature thus represents the basic intertex of the African imagination.

Ensaístas como Emmanuel Obiechina, ou Ato Quayson, desenvolveram, em obras publicadas na década de noventa, propostas muito úteis para este 
estudo das representações da oralidade, que vêm complementar as propostas francófonas, anteriormente formuladas por Kane e Ngal.

Os trabalhos críticos, produzidos com base neste modelo, pela crítica africana em língua portuguesa, fundamentaram-se, em grande parte, em ensaios provenientes da bibliografia francófona e anglófona, no entanto, adequando-a à textualidade em língua portuguesa. Deve-se destacar a obra de Salvato Trigo sobre Luandino Vieira, que foi um dos ensaios pioneiros nesta área de pesquisa. Neste estudo da obra de Luandino constatamos um primeiro momento de representação da oralidade, que passa necessariamente pela língua.

Saliente-se, também neste percurso analítico das representações da oralidade na literatura angolana, o livro de Laura Padilha, Entre Voz e Letra - o lugar da Ancestralidade na Ficção Angolana do século XX, resultado da sua tese de doutoramento, que retoma alguns destes problemas, em especial, ao desenvolver aspectos relacionados com o género. $\mathrm{O}$ trabalho que também nós viémos a desenvolver sobre a obra poética de José Craveirinha, de certo modo executa um percurso semelhante. Este tipo de orientação veio a ser repensado teoricamente, numa outra tese, A Construção da Imagem de Moçambicanidade em José Craveirinha, Mia Couto e Ungulani Ba Ka Khosa, da autoria de Gilberto Matusse.

É partindo de algum deste enquadramento crítico, acerca da literatura moçambicana, que reflectimos agora sobre a vertente pragmática destas representações da oralidade com o estudo da obra de Ungulani Ba Ka Khosa, Ualalapi, o primeiro romance moçambicano que visa tematicamente a questionação do passado histórico, fazendo uma releitura das fontes históricas da época anterior ao início da colonização portuguesa. A obra concretiza uma reflexão sobre a noção de cultura e identidade cultural, que é retrabalhada pela reabsorção de modelos de oralidade e de uma certa mundividência mágico-mítica.

O tempo invocado em Ualalapi é a época pré-colonial, e as narrativas organizam-se em torno da personagem Ngungunhane, imperador nguni que reinava na área geográfica, que corresponde, ao que é hoje, o sul de Moçambique. As últimas narrativas da obra situam-se já na época colonial, com a vitória dos portugueses nas campanhas de ocupação, e a partida do imperador, derrotado, num barco, para o que seria o seu exílio açoriano.

Ualalapi, designado como romance, organiza-se num conjunto de seis contos, que funcionam como unidades independentes, e ao mesmo tempo 
interdependentes. Cada uma das narrativas é precedida de um pequeno texto em itálico (muitas vezes com atribuição de autoria, outras vezes deprendese que são do autor da obra, e oscilando entre o testemunho histórico e a ficção), intitulado, Fragmentos do fim, numerados de um a seis, que estabelecem uma evolução e quadro cronológicos, até à queda do império nguni.

Estes fragmentos e outras citações de abertura, encontradas em Ualalapi, podem ser consideradas declarações de intenção paratextuais, declarações estas que o crítico M. Ngal, no texto teórico de Mateso, considera reveladoras dos propósitos de representação da oralidade.

Os contos sucedem-se a estes textos, e a sua temporalidade, situa-se numa dimensão mais indefinida e mítica, num continuum intemporal, com ausência de tempo cronológico. Este entrecruzar entre o tempo histórico e o míticolendário, prevalecente, mostra que o romancista moçambicano integra uma temporalidade, característica da literatura oral, no decorrer da narrativa, a fim de insistir na função didáctica e moralizante, própria dos universos orais, em que a repetição atemporalizada dos enredos se adequa, criticamente, a qualquer época.

A escolha do conto como unidade narrativa leva-nos de imediato a considerar a opção, como sendo adequada a um universo cultural que radica na oralidade. Esta narrativa é um todo, fragmentado em histórias que, aditivamente, vão esclarecendo e diferindo os sentidos.

As narrativas da tradição oral africana têm uma forte componente didácticomoralizante. Isto reflecte-se na sua estruturação, através do carácter e da seqüência das suas transformaç̧ões. Com efeito, algumas classificações tipológicas destas narrativas têm como critério fundamental o sentido da transformação que altera a situação inicial e determina a situação final da história, e que pode ser de degradação e de melhoramento. Distinguem-se dois tipos básicos de narrativas: as de tipo ascendente e as de tipo descendente, conforme apresentem uma transformação de melhoramento ou de degradação, respectivamente. O carácter didáctico das de tipo descendente está na exemplificação da punição de um anti-herói pela transgressão das regras, enquanto que, no caso oposto, no prémio pela exemplaridade heróica.

$\mathrm{Na}$ quase totalidade dos contos-romance de Khosa, apesar da complexidade de estrutura, própria de uma narrativa escrita, insinua-se, como refere Gilberto Matusse, uma sucessão de transformações baseadas no modelo das 
narrativas de tipo descendente, em que o protagonista comete uma transgressão às normas vigentes na sua comunidade, para daí obter benefícios, acabando, no entanto, por ser punido por essa mesma transgressão. A recuperação deste modelo, mais ou menos linear, está naturalmente absorvida e retrabalhada de modo poliforme. Estes aspectos confirmam a mobilidade temporal e espacial, enquanto formas de sobrevivência da literatura oral que caracterizam o romance africano, conforme se assinalou no texto de Locha Mateso, com os tópicos adiantados por Kane, em que o itinerário do herói evolui na mudança, partindo de uma situação de desquilíbrio ou equilíbrio, que tende a inflectir no seu contrário, prevalecendo uma moralidade final.

No que respeita ao aspecto temático, há, também, uma insistência na reivindicação de valores culturais outros, de que a tradição oral e suas formas fazem eco, como por exemplo as práticas e crenças animistas, a dimensão mítico-mágica do universo, a singularidade dos costumes e códigos sociais.

A narrativa "Diário de Manua" prefigura, neste sentido, algumas das questões problematizantes relativas à valorização do universo da oralidade, por oposição à escrita, metáfora da inscrição colonial. Manua é nguni, filho de Ngungunhane. Tirou um curso de artes e ofícios e deixou escrito um diário, do qual o narrador se socorre para nos dar informações. Representa o assimilado, não é reconhecido pelos seus, nem pelos brancos. Transgride os valores e a tradição da sua cultura, e por isso é punido com a morte.

Manhune transmitira ao filho e ao neto de que Manua fora envenenado pelo pai, pois era uma vergonha para os nguni ver um filho seu assimilar costumes de outros povos estrangeiros, e o pior, dizia Manhune, Manua parecia um chope, pois era subserviente aos portugueses. Matem-no na próxima oportunidade, disse Ngungunhane num dos encontros que teve com os maiores do reino. ( $p$ 106)

O conto "Diário de Manua" começa aliando a idéia de decadência do império com o achado do diário. A escrita é aqui, por um lado, o símbolo maior da recusa da cultura tradicional, por outro do início do colonialismo, enquanto rasura e transformação de valores dessa mesma cultura.

Sabe-se, historicamente, que foram os árabes e os europeus a introduzirem a escrita em África, e neste conto faz-se referência a um árabe, e ao seu testemunho escrito, que complementa os registos de Manua. Estas duas personagens testemunham o início da quebra de uma tradição de oralidade e a componente irreversível da transformação da sociedade pré-colonial. 
Por entre os escombros daquilo que fora a última capital do império de Gaza encontraram um diário com uma letra tremida, imprecisa, tímida, as folhas amontoadas ao acaso, estavam metidas numa caveira que repousava entre ossadas humanas e animais... Não há referência ao seu autor, mas sabe-se que pertenceu a Manua, filho de Ngungunhane (p.97)... De 1892 a 1985, ano de sua morte, o diário nada diz, pois a folhas foram comidas pelos ratos, as letras que restaram estão soltas. Juntando as cinco letras tem-se a palavra morte. Ou temor. Ou tremo. Kamal Samade, que pela capital passou, deixou as suas impressões em árabe, escritas em folhas desordenadas. Pela sua pena sabe-se que Manua, desde a chegada tornou-se taciturno e mais bêbado do que nunca. (p.105)

A imposição da escrita, numa sociedade de tradição oral, é um elemento de desequilíbrio. A escrita aqui não é um produto da evolução histórica normal e responde a uma necessidade imposta pelo exterior. Por outro lado, a desvalorização das formas de culturas indígenas, que caracterizou a política colonial de assimilação, contribuiu para a descaracterização e rasura de valores ancestrais.

Khosa ao tematizar a revalorização da oralidade, encontra uma forma de manifestar a recuperação simbólica desse estado civilizacional, anterior à introdução da escrita, em Moçambique, reivindicando uma reposição de valores próprios, portanto, também um meio de afirmação de uma cultura outra, que foi subjugada pela hegemonia da escrita.

A este propósito é importante recordar que a oralidade é o domínio da cultura peculiar à maioria da população moçambicana, essencialmente rural e camponesa. Por outro lado, se o oral coincide com o popular, este domínio da tradição oral é conotado com a camada considerada depositária. Valorizar esse domínio é uma forma de conhecer e respeitar, reaver, talvez, contributos importantes para a recriação e reformulação de uma cultura nacional.

Neste conto, "Diário de Manua", patenteia-se, de forma relativamente explícita, uma espécie de moral ou função didáctica: o narrador, ao problematizar o significado da escrita na sociedade moçambicana, denega o seu valor, socorrendo-se parodicamente de uma estratégia temático-formal, a invenção de fontes escritas, o diário achado de Manua e o testemunho do árabe. Estas fontes forjadas no interior do texto permitem-lhe reflectir, com ironia, sobre o abandono da oralidade, e a cultura que ela representa, enquanto uma das causas da degradação cultural. 
Khosa utiliza ainda outros processos característicos da narrativa oral, a intervenção do sobrenatural. É característica das narrativas orais as personagens possuírem poderes mágicos, e viverem acontecimentos de ordem mágica, bem como terem de se defrontar com inimigos possuidores desses poderes, ou serem afectados por fenómenos sobrenaturais. Nesta obra, a presença de elementos sobrenaturais é quase constante, sendo as situações mais freqüentes as que envolvem a estranheza e a desproporção de fenómenos físicos e da natureza.

A incorporação do imaginário tradicional é uma das características distintivas desta obra moçambicana. Há uma valorização das crenças animistas, de códigos outros, radicados no passado, a que se atribui um valor sagrado. A isto não é certamente estranho o facto de a memória das sociedades de tradição oral se cristalizar em torno dos antepassados ancestrais. $\mathrm{O}$ passado institui-se como uma referência insubstituível, à qual a comunidade vai buscar a inspiração para a sua conduta no presente, bem como o exemplo para a explicação dos fenómenos com que se depara.

O carácter sagrado detecta-se numa atmosfera cujo equilíbrio precário depende da observância das normas, tornando-se a sua explicação ou caracterização inacessíveis, pelos menos aos não iniciados. A escolha de um cenário histórico, que se orienta para uma época longínqua e de contornos imprecisos, relembra a sacralidade da origem e da fundação.

O mundo de ficção de Khosa apresenta-se, deste modo, numa instabilidade generalizada, é um mundo em desintegração. As causas deste desmoronar estão ligadas ao desrespeito pelo sistema de valores tradicionais, próprios da cultura pré-colonial. Ao trazer as formas, e ao recriar um certo imaginário da tradição oral na sua obra, Khosa deseja provavelmente chamar a atenção para a cultura anulada e considerada como superstição nos primeiros anos de independência, que procurou eliminar os valores do mundo tradicional.

Trata-se de uma caracterização do caos em que a sociedade mergulha com as viragens operadas, primeiro pelo colonialismo, depois pela independência. Há efectivamente uma série de valores ideológicos que acompanham o novo poder, a partir de 1975, que entram em conflito com crenças e práticas de tradições. Ao reportar-se a um outro tempo histórico, com alguma nostalgia, o narrador quer também, e em especial, referir o tempo actual, aquele em que vive. Curiosamente a numerologia simbólica, que aparece repetida 
para designar o tempo mítico, refere o número onze, como emblemático. Onze noites, onze dias, onze anos de governação de Ngungunhane, onze anos de governação marxista de Samora Machel, na primeira fase pós-independência.

Por outro lado Ungulani Ba Ka Khosa, com o seu livro, Ualalapi, moderniza a ficção moçambicana ao introduzir um género, que se enraíza no romance histórico. Os sinais que nos permitem identificar o género são os nomes de personagens históricos e os acontecimentos que nos convidam a ler o texto à luz de um certo conhecimento histórico. Contudo, o modelo do género escolhido não tem a ver com o romance histórico romântico, mas antes com algumas das estratégias de ficção histórica moderna e pós-moderna, bem como com a recuperação simultânea da genologia oral africana, nomeadamente ao fazer do conto a forma de construção romanesca da sua escrita.

Esta obra vem confirmar o entrosamento cultural da literatura moçambicana, que burila, de forma mais ou menos consciente, a sua originalidade na recriação e partilha de dois universos culturais: o europeu, que lhe legou a escrita, e o pré-colonial, de que reinventa, através da escrita, a fictiva ancestralidade e as formas orais.

O livro termina com o conto "O Último discurso de Ngungunhane" que nos interessa aqui destacar por vários motivos de ordem simbólica, narratológica e temática.

Virou-se repentinamente para a multidão que o vaiava, a uns metros do paquete que o levaria para o exílio, e gritou como nunca, silenciando as aves (...) Ngungunhane falando, e o corpo bojudo oscilando para a direita e para a esquerda, enquanto os olhos reluziam e as tremiam ao ritmo das palavras que cresciam, de minuto a minuto, como agora, em que Ngungunhane dizia a todos, podeis rir, homens, podeis aviltar-me, mas ficai sabendo que a noite voltará a cair nesta terra amaldiçoada... (p.115).

A forma como é descrita a profecia do imperador, convoca-nos a um paralelismo com certas das formas das punições, descritas anteriormente na obra. A profecia apocalíptica silencia e aterroriza os tsongas pela sua carga tremenda de maldições. O imperador punido, acusa a aliança dos moçambicanos com os estrangeiros. Pela primeira vez, apesar da sua figura 
histriónica, a personagem é apresentada com alguma dignidade, como sendo portadora de um saber/poder oculto, com que se faz, mais uma vez, temer. Desta vez não apenas por razões de poder temporal, mais pelo uso da palavra que o transcende.

O discurso de Ngungunhane, nesta narrativa, projecta-se até à actualidade, prevendo os males do colonialismo, a guerra pela independência e a guerra civil pós- independência. Carregado de hipérboles, imagens abjectas e visões aterradoras, a sua palavra refere o ódio, as pragas, doenças hereditárias, violência cultural, desprezo pela cultura tradicional, humilhação física, violação de mulheres, usurpação das terras, prisões e torturas, sujeição a novas práticas religiosas, assimilação linguística e, posteriormente, todas as atrocidades da guerra civil.

A profecia de carácter apocalíptico neste conto, enquanto discurso, estabelece uma relação entre o sujeito e o transcendente, tornando-se aquele portador de uma verdade futura, antecipadamente anunciada. A profecia é característica por excelência de sociedades cuja tradição é oral, e cumpre-se através da palavra dos mediadores, profetas ou feiticeiros. Mais uma vez deparamos com uma estratégia, por parte do narrador, de tematização e de recuperação da oralidade, ao colocar na boca do seu protagonista este tipo de discurso.

Observamos ao longo da narrativa de Khosa, e neste discurso em especial, a manipulação do narrador de forma a aproximá-lo do contador, encarnando aquele a polivalência do contador tradicional, que interfere e não hesita em invadir a narrativa e distanciar-se de novo e, tal como foi referido por M. Ngal, demonstra, por exemplo, que o narrador, como na tradição oral, desempenha um papel primordial, aproximando o acto de fala ao acto de criação.

Por outro lado, dada a sua temporalidade abrangente, a profecia permite relacionar o passado com o futuro, e com o presente, sendo, por isso, adequada, às intenções críticas da narrativa histórica. Devido às formas escolhidas, há neste processo narrativo, a valorização do tempo mítico que se sobrepõe ao histórico. Passado, presente e futuro mais não são mais do que conseqüências transcendentes e punitivas dos actos praticados pelos homens. É esta mundividência que o narrador imprime na sua escrita.

O narrador faz uso do discurso profético, recorrendo à tradição oral, à sobrevivência e vitalidade da palavra transmitida geração, após geração. O 
velho que serve de fonte ao narrador, retransmite o seu saber, adquirido através da voz do avô:

- Há pormenores que o tempo vai esboroando - disse o velho tossindo. Colocou duas achas no fogo e soprou. Novelos de fumo passaram pelo rosto. Pequenas lágrimas saíram dos olhos cansados e tocaram na pele coberta de escamas. Afastei os papéis. Olhei-o. Era noite.

- Era miúdo ainda - prosseguiu - quando o meu avô me contava histórias de Ngungunhane. (...) E ele, ao contar-me as histórias de Ngungunhane, repisava alguns aspectos que o meu pai se esquecia e que tu omitiste. E são pormenores importantes. (p.116/7)

Identificamos, nesta passagem, o narrador como testemunha, que finge ser imparcial. Ele ouve o velho no ambiente adequado, numa noite de lua cheia, em redor da fogueira. Contudo, a palavra que utiliza é escrita: "Afastei os papéis", que representa outro tempo, numa prática de reconfigurada modelação da mundividência pré-colonial à pós-colonial, que, por sua vez exige ao leitor, e ao crítico, uma leitura localizada das práticas históricas e culturais e, tal como insinua Achebe, em que o domínio do conceito de universal se torna pouco operatório.

Ualalapi de Ungulani $\mathrm{Ba} \mathrm{Ka}$ Khosa permite discutir parcimoniosamente, conto a conto, a importância do tratamento de questões como a representação da oralidade no domínio temático, do género, e da exploração dos imaginários míticos. Por outro lado, a obra permite, ainda, evidenciar a importância crescente na literatura moçambicana de um eixo temático nativista, em pleno desenvolvimento. 